linked to chromosome 17q21-22 (FTDP-17): Duke family 1684. J Neuropathol Exp Neurol 1999;58:859-866.

22. Murrell JR, Spillantini MG, Zolo P, et al. Tau gene mutation G389R causes a tauopathy with abundant Pick body-like inclusions and axonal deposits. J Neuropathol Exp Neurol 1999; $58: 1207-1226$.

23. van Swieten JC, Stevens M, Rosso SM, et al. Phenotypic variation in hereditary frontotemporal dementia with tau mutations. Ann Neurol 1999;46:617-626.

24. Arima K, Kowalska A, Hasegawa M, et al. Two brothers with frontotemporal dementia and parkinsonism with an N279K mutation of the tau gene. Neurology 2000;54:1787-1795.

25. Tolnay M, Spillantini MG, Rizzini C, et al. A new case of frontotemporal dementia and parkinsonism resulting from an intron $10+3$-splice site mutation in the tau gene: clinical and pathological features. Neuropathol Appl Neurobiol 2000;26:368-378.

26. Yasuda M, Takamatsu J, D’Souza I, et al. A novel mutation at position +12 in the intron following exon 10 of the tau gene in familial frontotemporal dementia (FTD-Kumamoto). Ann Neurol 2000;47:422-429.
27. Spillantini MG, Goedert M, Crowther RA, et al. Familial multiple system tauopathy with presenile dementia: a disease with abundant neuronal and glial filaments. Proc Natl Acad Sci USA 1997;94:4113-4118.

28. Spillantini MG, Bird TD, Ghetti B. Frontotemporal dementia and parkinsonism linked to chromosome 17: a new group of tauopathies. Brain Pathol 1998;8:387-402.

29. Spillantini MG, Yoshida H, Rizzini C, et al. A novel tau mutation $(\mathrm{N} 296 \mathrm{~N})$ in familial dementia with swollen achromatic neurons and corticobasal inclusion bodies. Ann Neurol 2000; 48:939-943.

30. Rizzini C, Goedert M, Hodges JR, et al. Tau gene mutation K257T causes a tauopathy similar to Pick's disease. J Neuropathol Exp Neurol 2000;59:990-1001.

31. Spillantini MG, Crowther RA, Goedert M. Comparison of the neurofibrillary pathology in Alzheimer's disease and familial dementia with tangles. Acta Neuropathol 1996;92:42-48.

32. Feany MB, Dickson DW. Widespread cytoskeletal pathology characterizes corticobasal degeneration. Am J Pathol 1995; 146:1388-1396.

\title{
The relationship of hypertension in the elderly to AD, vascular dementia, and cognitive function
}

\author{
H.B. Posner, MD; M.-X. Tang, PhD; J. Luchsinger, MD; R. Lantigua, MD; Y. Stern, PhD; and \\ R. Mayeux, MD
}

\begin{abstract}
Background: Hypertension at the age of 45 to 50 years may predispose to AD later in life. It is not known whether hypertension after age 65 years also contributes to $\mathrm{AD}$ risk, and its effect on cognitive function is also not fully understood. Methods: Data were analyzed from 1,259 Medicare recipients free of dementia in a longitudinal study covering a 7-year period (1991 to 1998). The effect of hypertension was first examined in relationship to the risk for incident AD and then to incident vascular dementia $(\mathrm{VaD})$ using Cox proportional hazards models. Changes in performance over time on tasks of memory, language, and visuospatial/cognitive function were compared in those with and without hypertension using generalized estimating equations. Results: Of the 1,259 subjects, 731 (58.1\%) had a history of hypertension associated with diabetes, stroke, and heart disease. A history of hypertension was not associated with an increased risk for $\mathrm{AD}$ (rate ratio $[R R]$ 0.9, 95\% CI 0.7 to 1.3) but was associated with an increased risk for $\mathrm{VaD}$ (1.8 [1.0 to 3.2]). Hypertension was not associated with changes in memory, language, and general cognitive function in normal individuals over time. Compared with individuals with neither hypertension nor heart disease, those with hypertension or heart disease alone had no increase in risk for $\mathrm{VaD}$. However, when both were present, there was a threefold increase in risk for VaD. A sixfold increase in risk was observed when both hypertension and diabetes were present. Conclusions: Hypertension after age 65 years is not associated with $\mathrm{AD}$ and does not adversely affect memory, language, or general cognitive function. A history of hypertension may be an antecedent to $\mathrm{VaD}$, particularly in the presence of heart disease or diabetes.
\end{abstract}

NEUROLOGY 2002;58:1175-1181

Hypertension has been associated with the later development of $\mathrm{AD}$ and vascular dementia $(\mathrm{VaD})$, $^{1-6}$ though this is disputed..$^{7}$ Hypertension is thought to act over years by decreasing the elasticity of vessels, increasing resistance, and reducing responsiveness to momentary changes in tissue demands. ${ }^{3,8,9}$ Atherosclerosis is one of the mechanisms that give rise to increased vascular wall tension. Atherosclerosis, mea-

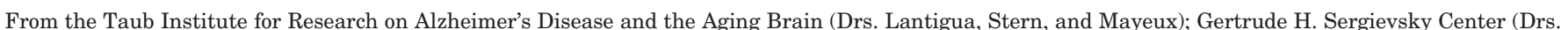

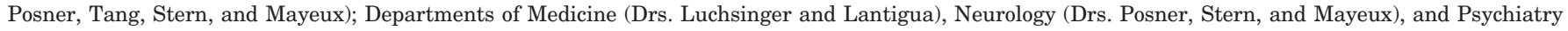

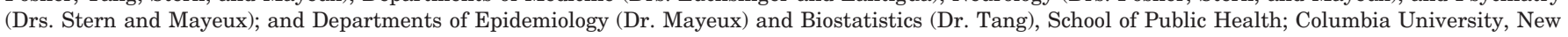
York, NY.

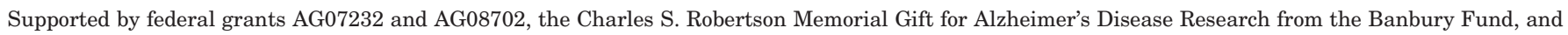
the Blanchette Hooker Rockefeller Foundation.

Received September 6, 2001. Accepted in final form January 8, 2002.

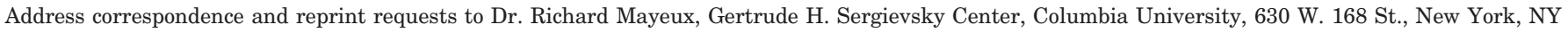
10032; e-mail: rpm2@columbia.edu 
sured directly by carotid ultrasound, may be related to peripheral blood pressure and has been associated with both $\mathrm{AD}$ and $\mathrm{VaD} .{ }^{10}$ Because hypertension is frequent in the elderly, we hypothesized that it might also be a risk factor for $\mathrm{AD}$ or $\mathrm{VaD}$.

Methods. Study population. Data were derived from participants in the Washington Heights-Inwood Columbia Aging Project identified from a random sample of healthy Medicare beneficiaries 65 years or older residing in northern Manhattan between 1991 and 1996. The sampling procedures have been described elsewhere. ${ }^{11}$ Participants underwent an in-person, structured interview of health and function at the time of study entry, followed by a standard medical history, physical and neurologic examination, and neuropsychological battery. Participants were followed at approximately 18-month intervals, repeating the evaluations used at baseline at each follow-up. Only individuals who completed at least one follow-up were included in the analyses.

Of the 2,126 individuals who underwent baseline assessment, $327(15.4 \%)$ were demented and excluded from the subsequent analysis. Data were not available for 540 (25.4\%) of the cohort: $142(6.7 \%)$ died before follow-up, 396 $(18.9 \%)$ either refused further involvement with the study or moved out of the area, and $2(0.09 \%)$ had missing hypertension history data. These 540 individuals were similar to the study sample in sex, education, distribution of $A P O E$ genotype, and frequency of a history of stroke, hypertension, and smoking. Those who remained in the study were younger: 75.7 vs 77.0 years old $(p<0.001)$. There were also more Hispanics than whites or African Americans remaining in the study. Those who remained were less likely to have diabetes $(13.3 \%$ vs $20.2 \% ; p=0.0005)$ or heart disease (21.8\% vs $26.0 \% ; p=0.05)$. The remaining sample included 1,259 (59.2\%) that were available for longitudinal analysis. The Columbia University Institutional Review Board reviewed and approved this project. All individuals provided written informed consent.

Clinical assessments. Physicians completed standardized medical and neurologic histories and examinations, and subjects underwent a standardized neuropsychological test battery testing multiple domains in either Spanish or English. Orientation was evaluated using parts of the modified Mini-Mental State Examination..$^{12}$ Language was assessed using the Boston Naming Test, ${ }^{13}$ the Controlled Word Association test ${ }^{14}$ category naming, and the Complex Ideational Material and Phrase Repetition subtests of the Boston Diagnostic Aphasia Evaluation..$^{15}$ Abstract reasoning was tested using the Abstract Reasoning and Similarities subtests from the Wechsler Adult Intelligence Scale-Revised (WAIS-R), ${ }^{16}$ the nonverbal Identities and Oddities subtest of the Mattis Dementia Rating Scale, ${ }^{17}$ the Rosen Drawing Test, ${ }^{18}$ and a matching version of the Benton Visual Retention Test. ${ }^{19}$ Memory was evaluated using the multiple-choice version of the Benton Visual Retention Test ${ }^{19}$ and seven subtests of the Selective Reminding Test $^{20}$ : total recall, long-term recall, long-term storage, continuous long-term storage, words recalled on last trial, delayed recall, and delayed recognition. This neuropsychological battery had been validated in the same geographic area. ${ }^{21,22}$

Results of these examinations were reviewed by a group of physicians and neuropsychologists who reached consensus regarding the presence or absence of dementia using published criteria for probable and possible $\mathrm{AD}^{23}$ and VaD. ${ }^{24}$ Severity of $\mathrm{AD}$ was rated using the Clinical Dementia Rating Scale (CDR). ${ }^{25}$ Only those individuals with CDR scores of $\geq 1.0$ were considered as cases for the initial analyses. Individuals who had CDR ratings of $\leq 0.5$ remained in the comparison group.

Brain imaging was available in $85 \%$ of cases with a history of stroke; in the remainder, stroke was defined by World Health Organization criteria. ${ }^{26}$ Subjects without dementia at baseline, but with stroke, were included in the analyses.

Ethnic group. At baseline, ethnic group was documented by self-report using the format of the 1990 US Census. ${ }^{27}$ Individuals were first asked to indicate their racial group and then whether or not they were of "Hispanic origin."

Hypertension. At baseline, all participants were asked whether or not they had a history of hypertension (high blood pressure) at any time during their life. If affirmative, they were asked whether or not they were under treatment and the specific type of treatment. Blood pressure was also recorded at each visit using the Dinamap Pro 100 (Critikon Co., Tampa, FL). The blood pressure cuff was placed on the right arm while the individual was seated, and a recording was obtained every 3 minutes over 9 minutes. The third measurement was recorded in the database. Values above $140 \mathrm{~mm} \mathrm{Hg}$ (systolic) and $90 \mathrm{~mm} \mathrm{Hg}$ (diastolic) were used as criteria for hypertension. ${ }^{28}$ For analytic purposes, we reclassified measured blood pressure using the guidelines suggested in the Sixth Report of the National Committee on Prevention, Detection, Evaluation, and Treatment of High Blood Pressure. ${ }^{29}$

Other medical information. At the baseline interview, all participants received a standardized interview concerning a history of medical illnesses (e.g., diabetes, cancer) at any time during their lives. If affirmative, they were asked about the type of treatment received.

APOE genotype. Genotypes were obtained by amplification of genomic DNA with PCR subjected to $C f o$ I restriction analysis using $A P O E$ primers and conditions similar to those described by Hixson and Vernier ${ }^{30}$ and modified by Maestre et al. ${ }^{31}$

Data analysis. Continuous variables were compared using analysis of variance, and categorical variables were compared using $\chi^{2}$ tests. Cox regression models were used with the exposure being a history of hypertension and the outcome either $\mathrm{AD}$ or $\mathrm{VaD}$. Patients who met criteria for possible $\mathrm{AD}$ with a history of stroke were classified as possible $\mathrm{AD}$ for the analyses regarding $\mathrm{AD}$ and as $\mathrm{VaD}$ for the studies regarding that outcome. Baseline information was used for all covariates including age, education, and a history of diabetes or heart disease. Heart disease was defined as a history of myocardial infarction, congestive heart failure, or angina. For these regression analyses, we set $\alpha=0.05$ and $\beta=0.20$. With a fixed sample size of 1,259 , the exposure of hypertension and the confounders of diabetes and heart disease, the lowest detectable risk ratio (RR) for $\mathrm{AD}$ was 1.68 and for $\mathrm{VaD} 2.5$. To assess for effect modification by other vascular diseases, dummy variables were created and used in Cox regression models.

A factor analysis was performed using data from the 
Table 1 Baseline characteristics of individuals who did and did not develop dementia

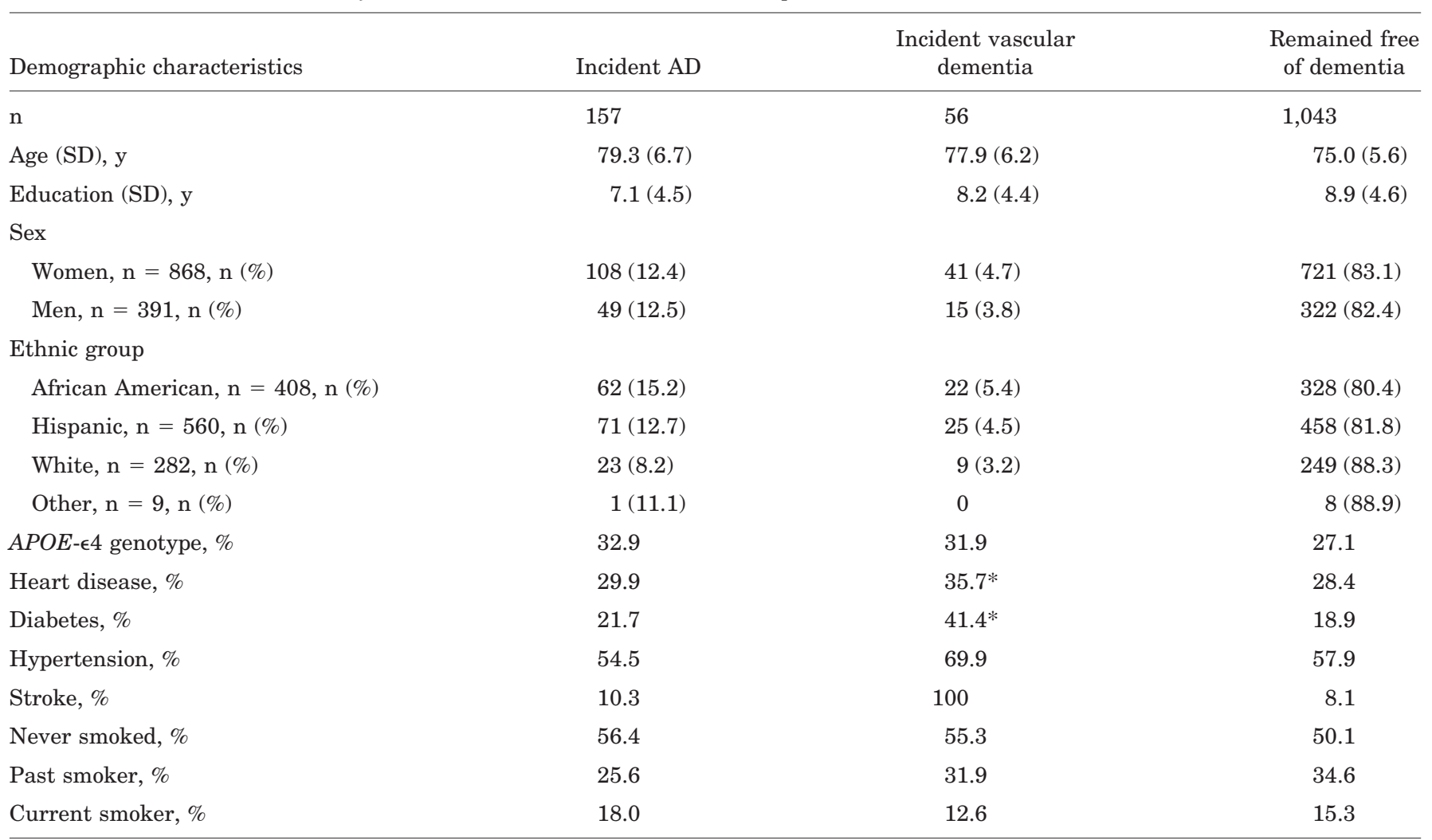

Nineteen patients with other dementia are not shown. There is overlap in the vascular dementia category as 16 patients met criteria for possible $\mathrm{AD}$ and vascular dementia. Their data are included in both columns and analyses.

$* p<0.05$.

entire cohort with the 15 neuropsychological measures using a principal component analysis with varimax rotation and Kaiser normalization. ${ }^{32}$ This analysis yielded three factors: 1) a memory factor, where the seven subtests of the Selective Reminding Test were the main contributors; 2) a visuospatial/cognitive factor, in which visuospatial and tests of reasoning were the main contributors; and 3) a language factor, where language measures from the Boston Naming Test, ${ }^{13}$ Controlled Oral Word Association test, ${ }^{14}$ and the WAIS-R Similarities ${ }^{16}$ were the main contributors. Component scores for each participant at each visit were calculated by adding the scores of the measures that contributed most to each factor. Each factor score was normally distributed (skewness: memory 0.8, language -0.6 , visuospatial/cognitive 0.7 ).

Generalized estimation equations $(\mathrm{GEE})^{33}$ were used to examine changes in each neuropsychological domain over time. The dependent variables were the factor scores, and the independent variables were baseline history of hypertension and time, included as a continuous variable. The GEE analyses yield $\beta$ values that represent the strength of the associations between factor scores and variables included in the model. A significant group effect indicates a difference between two groups at the baseline or at any subsequent interval. A positive value for $\beta$ indicates that the group with a specific variable performed better than the group without that variable. A significant time effect indicates a change in a factor score over the total duration of follow-up. A significant interaction effect indicates a difference in the rate of change in a factor score depending on the presence of the covariate.

Results. Of the initial 1,259 participants, $731(58.1 \%)$ reported a history of hypertension at baseline. Compared with individuals without hypertension, those with hypertension were more likely to report a history of heart dis-

Table 2 Proportional hazards model to assess risk for AD or vascular dementia (VaD) by history of hypertension

\begin{tabular}{lccccc}
\hline Hypertension & Total at risk & Developed AD, n (\%) & AD, RR (95\% CI) & Developed VaD, n (\%) & VaD, RR (95\% CI) \\
\hline Present & 731 & $84(11.5)$ & $0.9(0.7-1.3)$ & $39(5.3)$ & $1.8(1.0-3.2)^{*}$ \\
Absent & 528 & $73(13.8)$ & 1.0 (reference) & $17(3.2)$ & $1.0($ reference) \\
\hline
\end{tabular}

Unadjusted risk ratio (RR) and 95\% CI are shown. When $\mathrm{AD}$ model was repeated adjusting for age, education, ethnic group, and history of heart disease, the RR decreased to 0.8 (95\% CI, 0.6-1.1). Similarly, the RR decreased to 1.6 (0.9-2.9) for the VaD model when it was adjusted for these factors. The RR did not change when stratified by treatment.

$* p=0.05$. 
Table 3 Risk for $A D$ or vascular dementia $(V a D)$ by direct measurement of blood pressure

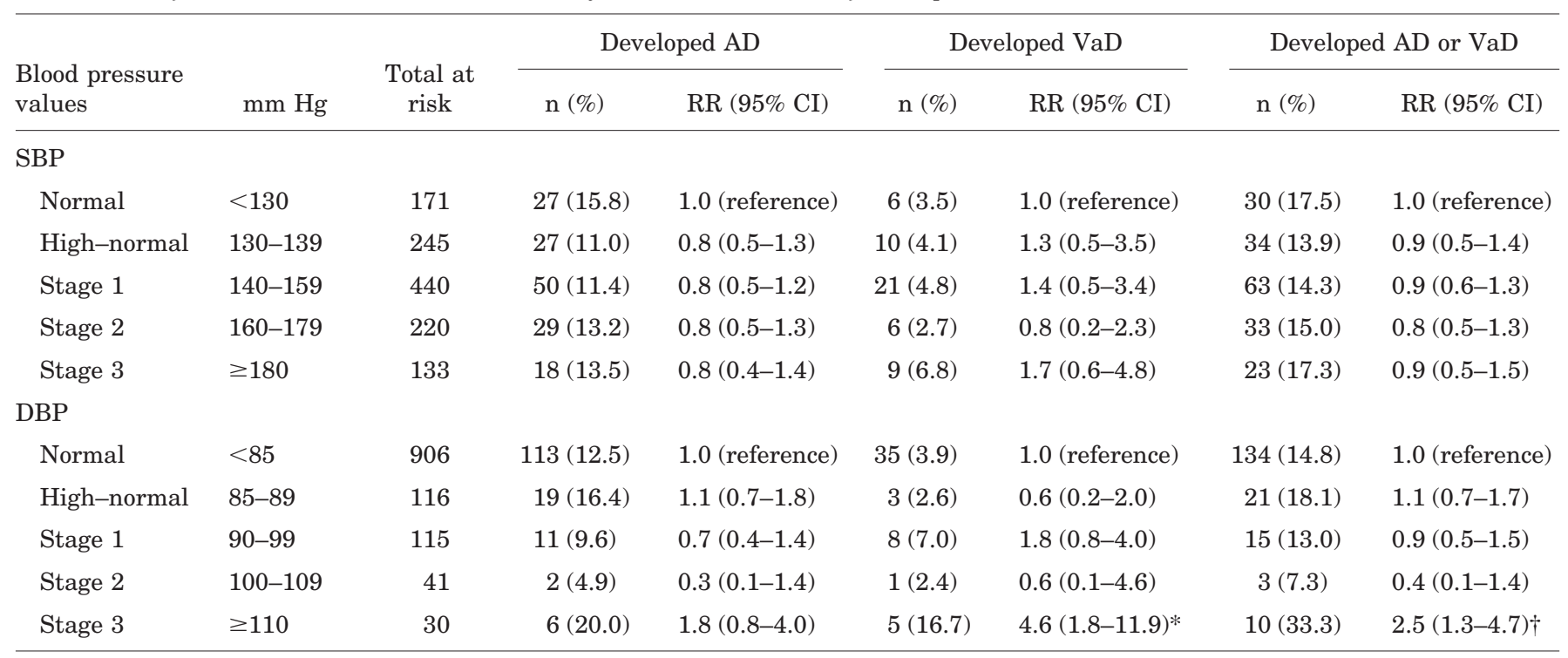

Direct measurement of blood pressure was classified by the Sixth Report of the National Committee on Prevention, Detection, Evaluation, and Treatment of High Blood Pressure. ${ }^{29}$

$* p=0.001$.

$\dagger p=0.006$.

$\mathrm{RR}=$ rate ratio $\mathrm{SBP}=$ systolic blood pressure $\mathrm{DBP}=$ diastolic blood pressure.

ease $(13.5 \%$ vs $27.8 \% ; p<0.0001)$, diabetes ( $15 \%$ vs $23.9 \%$; $p<0.0001)$, or stroke $(7.3 \%$ vs $12.8 \% ; p<0.006)$. Those without hypertension more frequently were smokers than those with hypertension $(19.1 \%$ vs $12.8 \%$; $p<0.01)$.

A history of hypertension was validated by direct measurement of blood pressure. The average systolic blood pressure for those without a history of hypertension was $143 \mathrm{~mm} \mathrm{Hg}$ and diastolic $73 \mathrm{~mm} \mathrm{Hg}$, whereas those with a history of hypertension, either treated or untreated, had average blood pressures of $154 \mathrm{~mm} \mathrm{Hg}$ systolic and $78 \mathrm{~mm}$ $\mathrm{Hg}$ diastolic. With use of the criteria for hypertension, ${ }^{28}$ the sensitivity and specificity were 76 and $48 \%$ for systolic hypertension and 85 and $35 \%$ for diastolic hypertension. The values for sensitivity and specificity did not differ for those with and without AD.

Over the 7 years of follow-up, AD developed in 157 $(12.5 \%)$ of the 1,259 participants. The proportion of males and females who developed $\mathrm{AD}$ was similar, but $\mathrm{AD}$ was more frequent in African Americans than Hispanics or whites. Compared with those who remained free of dementia, those who developed AD had fewer years of education. At baseline, neither a history of hypertension, diabetes, heart disease, or stroke nor the presence of the $A P O E-\epsilon 4$ genotype differentiated who would develop $\mathrm{AD}$ with $\mathrm{CDR}$ of $>1$ (table 1$)$.

$\mathrm{VaD}$ developed in 56 (4.4\%) of the 1,259 study participants during the 7 years of follow-up. The proportion of males and females who developed $\mathrm{VaD}$ was similar, as were the proportion of whites, African Americans, and Hispanics, though the numbers in each group were small. Compared with those who remained free of dementia, those with a baseline history of heart disease or diabetes were more likely to develop $\mathrm{VaD}$. Neither age nor the presence of the $A P O E-\epsilon 4$ genotype nor prior smoking history differentiated who would develop $\mathrm{VaD}$ (see table 1).

A history of hypertension was not associated with an increased risk for $\mathrm{AD}$ (table 2). The incidence rate of $\mathrm{AD}$ without a history of hypertension was $2.9 \%$ /person-year, and with a history of hypertension it was $3.1 \% /$ personyear. Adjustment for age, education, heart disease, and ethnic group had no effect on the relationship. No additive or synergistic effects were found between hypertension and other vascular risk factors and the relationship to $\mathrm{AD}$ risk. Treatment of hypertension did not affect risk estimates for $\mathrm{AD}$ (no treatment: RR $0.96,95 \%$ CI 0.6 to 1.5 ; treated: $0.86,0.6$ to 1.2 ).

The incidence of $\mathrm{VaD}$ among those without a history of hypertension was $4.2 \%$ /person-year, but with a history of hypertension, it increased to $8.6 \%$. Compared with those without hypertension, the relative risk for $\mathrm{VaD}$ among persons with a history of hypertension was nearly twofold higher (see table 2). Adjustments for age, education, sex, ethnicity, $A P O E-\epsilon 4$ status, and history of heart disease or smoking diminished this relationship (see table 2). Treatment of hypertension again did not affect risk estimates for $\mathrm{VaD}$ (no treatment: RR 1.7, 95\% CI 0.8 to 3.6; treated: $1.7,0.9$ to 3.2 ). We repeated this analysis, excluding patients with $\mathrm{AD}$ and stroke classified as $\mathrm{VaD}$, and the $\mathrm{RR}$ increased (RR 2.1, 95\% CI 1.0 to $4.6, p=0.05$ ). Adjustment for confounders, diabetes, and heart disease again decreased the association (RR $1.8,95 \%$ CI 0.8 to 3.9). Diabetes was strongly associated with $\mathrm{VaD}$ (RR 2.7, 95\% CI 1.3 to $5.6, p=0.007$ ) in the model.

The sensitivity and specificity for a history of hypertension were 76 and $48 \%$ (systolic hypertension) and 85 and $35 \%$ (diastolic hypertension). We analyzed the association between hypertension and dementia in two ways. Using the classification of high blood pressure suggested by the Sixth Report of the National Committee on Prevention, Detection, Evaluation, and Treatment of High Blood Pressure, ${ }^{29}$ we examined the baseline systolic and diastolic blood pressure measurements. There was no relationship 
Table 4 Independent effects of history of hypertension and two vascular risk factors (heart disease and diabetes) on risk for AD

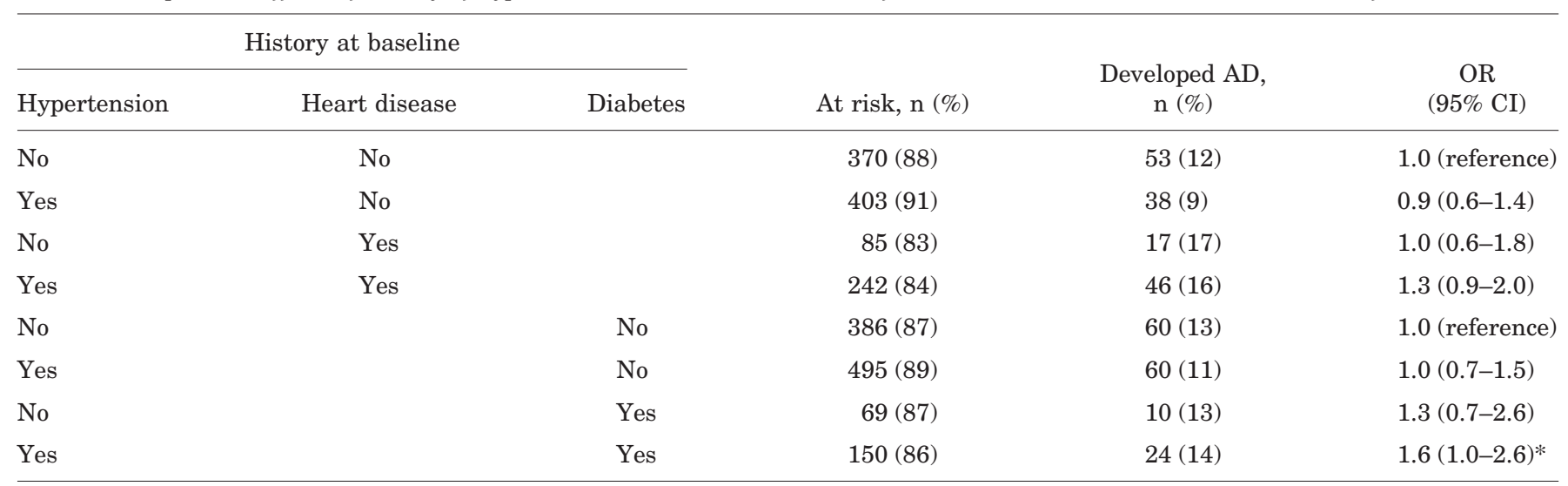

* Significant at $p<0.05$.

between any stage of high blood pressure and either $\mathrm{AD}$ or $\mathrm{VaD}$, with a single exception. A relationship between measured diastolic blood pressure values of $\geq 110 \mathrm{~mm} \mathrm{Hg}$ and incident $\mathrm{VaD}$ was found (RR 4.6, 95\% CI 1.8 to $11.9, p=$ 0.001) (table 3). However, there were only 30 individuals who had diastolic blood pressure values of $\geq 110 \mathrm{~mm} \mathrm{Hg}$, and only 5 of these developed VaD. Because many individuals reported both hypertension and other vascular diseases, we also investigated the independent and joint effects of hypertension and other vascular-related disorders on either $\mathrm{AD}$ or $\mathrm{VaD}$ (tables 4 and 5). Compared with individuals without hypertension or other vascular disorders, there was no increased risk for either $\mathrm{AD}$ or $\mathrm{VaD}$ among those with hypertension, heart disease, or diabetes. However, when hypertension and heart disease were reported together, the risk for $\mathrm{VaD}$ was greatly increased (RR 3.3, 95\% CI 1.7 to $6.6, p=0.0007$ ). The joint effects of diabetes and hypertension on $\mathrm{VaD}$ risk were also greatly increased (RR 6.2, 95\% CI 2.9 to $13.5, p<0.0001$ ). There was only a weak joint effect of hypertension and diabetes on $\mathrm{AD}$ risk.

GEE analysis in those without dementia revealed that the presence or absence of hypertension did not influence memory, language, or cognition performance over the follow-up period. The differences in slope were $0.19(-3.2$ to $3.6 ; p=0.46)$ for memory, $0.10(-0.14$ to $0.35 ; p=0.41)$ for language, and 0.45 ( -0.88 to $1.8 ; p=0.51)$ for general cognition.

Discussion. This prospective study of 1,259 participants over 7 years found no association between a history of hypertension and the development of $\mathrm{AD}$. When hypertension was classified using measured blood pressure, no evidence of association with $\mathrm{AD}$ existed. Moreover, hypertension did not affect memory, language, or general cognitive function over time.

Though there was an association between hypertension and $\mathrm{VaD}$, it was weak and may have been confounded by other variables. A significant relationship was found only when the diastolic blood pressure exceeded $110 \mathrm{~mm} \mathrm{Hg}$, which occurred in only a small number of individuals. Although it is possible that this finding was the result of a type 1 error from multiple comparisons, the association reached significance even after Bonferroni correction for 12 subcategories of high blood pressure $(p=0.004)$. The $\mathrm{RR}$ for the other categories of measured diastolic and systolic blood pressures were not consistent. Nonetheless, a weak association between elevated diastolic blood pressure and $\mathrm{VaD}$ could not be excluded.

When analyzed independently and jointly, an in-

Table 5 Independent effects of history of hypertension and two vascular risk factors (heart disease and diabetes) on risk for vascular dementia $(\mathrm{VaD})$

\begin{tabular}{|c|c|c|c|c|c|}
\hline \multicolumn{3}{|c|}{ History at baseline } & At risk, n (\%) & $\begin{array}{l}\text { Developed } \\
\text { VaD, n }(\%)\end{array}$ & $\begin{array}{c}\text { OR } \\
(95 \% \mathrm{CI})\end{array}$ \\
\hline Yes & No & & $430(98)$ & $11(2)$ & $1.1(0.5-2.4)$ \\
\hline No & Yes & & $99(97)$ & $3(3)$ & $0.8(0.2-2.8)$ \\
\hline Yes & & No & $534(96)$ & $21(4)$ & $1.9(0.9-4.0)$ \\
\hline No & & Yes & $74(94)$ & $5(6)$ & $3.2(1.1-9.2)^{*}$ \\
\hline Yes & & Yes & $156(90)$ & $18(10)$ & $6.2(2.9-13.5)^{*}$ \\
\hline
\end{tabular}

* Significant at $p<0.05$. 
teraction between hypertension and heart disease on $\mathrm{VaD}$ risk was found. Concurrent diabetes and hypertension appeared to have additive effects on $\mathrm{VaD}$ risk. Because heart disease, diabetes, and hypertension are common ailments in the elderly, the joint effects on the risk for $\mathrm{VaD}$ in the elderly need to be further investigated. However, in the absence of heart disease and diabetes, the relationship between $\mathrm{VaD}$ and hypertension remains tenuous.

The evidence favoring an association between hypertension and dementia, including $\mathrm{AD}$ and $\mathrm{VaD}$, has been most compelling for hypertension during middle age. ${ }^{2,34-37}$ Perhaps this is when other vascularrelated diseases are developing and the combined effects of these changes in the vasculature are becoming evident. Complications of hypertension, such as stroke, may trigger the onset of $\mathrm{AD},{ }^{38}$ though our results do not suggest the existence of an interaction between hypertension and stroke on $\mathrm{AD}$ risk. Treatment of hypertension may decrease $\mathrm{AD}$ risk in men, ${ }^{2}$ and the strength of the relationship between dementia and hypertension may vary with the severity of hypertension during middle age. ${ }^{4}$ Not all studies have verified a relationship between hypertension and $\mathrm{AD} .^{7}$

Skoog et al. ${ }^{6}$ found an association between hypertension at age 70 years and dementia 10 to 15 years later in a smaller cohort of 382 , where $<10 \%$ of the people became demented. Two hypertension treatment trials failed to reduce the incidence of cognitive decline, ${ }^{39-41}$ though differential dropout ${ }^{42}$ or the choice of drug may have contributed to the outcome. ${ }^{43}$ The Canadian Study of Health and Aging ${ }^{44}$ examined 105 patients who developed $\mathrm{VaD}$ over 5 years and found that hypertension was a significant risk factor only for females, but not males. Thus, it is possible that with longer follow-up of our cohort, a more definitive result would have emerged with regard to the association between hypertension and VaD. However, an earlier study ${ }^{45}$ using data from this same cohort showed that only diabetes was associated with the development of $\mathrm{VaD}$ and that there was no association between traditional vascular risk factors and $\mathrm{AD}$, thereby eliminating the possibility of confounding by these variables. Our finding of synergistic or additive effects on the risk for $\mathrm{VaD}$ between hypertension and either heart disease or diabetes has not been previously described.

A study of experimental hypertension in nonhuman primates revealed an association between cognitive and behavioral abnormalities and extravasation from vessels with impaired blood-brain barrier function. ${ }^{46}$ Although this might also be true in humans, the effects are acute. Further research needs to be done to clarify the relationship between each of the vascular risk factors and cerebral vessel dysfunction, especially because these effects may take time to develop.

We found no relationship between hypertension and changes in memory, language, or general cognitive function over follow-up of cognitively normal participants. Prior studies have used less detailed assessments of neuropsychological function ${ }^{3,5,47-49}$ or were cross-sectional in nature. ${ }^{47,49,50}$ Our use of GEE to evaluate longitudinal data provides the ability to measure the slope of performance as an indictor of change in each cognitive domain over the study period. There were no differences in the slopes for memory, language, and visuospatial/general cognition function in those with, compared with those without, hypertension.

A history of hypertension at age 65 years, treated or untreated, does not contribute to the development of $\mathrm{AD}$ and does not predispose to a decline in cognition, even without the development of dementia as people age. The association between hypertension and $\mathrm{VaD}$ is weak and may be related to concurrent vascular-related disorders so prevalent among the elderly.

\section{References}

1. Kivipelto M, Helkala EL, Laakso MP, et al. Midlife vascular risk factors and Alzheimer's disease in later life: longitudinal, population based study. Br Med J 2001;322:1447-1451.

2. Launer LJ, Ross GW, Petrovitch H, et al. Midlife blood pressure and dementia: the Honolulu-Asia aging study. Neurobiol Aging 2000;21:49-55.

3. Meyer JS, Rauch G, Rauch RA, Haque A. Risk factors for cerebral hypoperfusion, mild cognitive impairment, and dementia. Neurobiol Aging 2000;21:161-169.

4. Petrovitch H, White LR, Izmirilian G, et al. Midlife blood pressure and neuritic plaques, neurofibrillary tangles, and brain weight at death: the HAAS. Honolulu-Asia aging Study. Neurobiol Aging 2000;21:57-62.

5. Skoog I. Risk factors for vascular dementia: a review. Dementia $1994 ; 5: 137-144$.

6. Skoog I, Lernfelt B, Landahl S, et al. 15-year longitudinal study of blood pressure and dementia. Lancet 1996;347:11411145 .

7. Morris MC, Scherr PA, Hebert LE, Glynn RJ, Bennett DA, Evans DA. Association of incident Alzheimer disease and blood pressure measured from 13 years before to 2 years after diagnosis in a large community study. Arch Neurol 2001;58: 1640-1646.

8. Farkas E, De Vos RA, Jansen Steur EN, Luiten PG. Are Alzheimer's disease, hypertension, and cerebrocapillary damage related? Neurobiol Aging 2000;21:235-243.

9. Barbro BB. Hypertension. In: Welsh KMA, Caplan LR, Reis DJ, Seisjö BK, Weir B, eds. Primer on cerebrovascular diseases. New York: Academic Press, 1997:142-144.

10. Hofman A, Ott A, Breteler MM, et al. Atherosclerosis, apolipoprotein E, and prevalence of dementia and Alzheimer's disease in the Rotterdam Study. Lancet 1997;349:151-154.

11. Tang MX, Stern Y, Marder K, et al. The APOE-epsilon4 allele and the risk of Alzheimer disease among African Americans, whites, and Hispanics. JAMA 1998;279:751-755.

12. Folstein MF, Folstein SE, McHugh PR. "Mini-Mental State." A practical method for grading the cognitive state of patients for the clinician. J Psychiatr Res 1975;12:189-198.

13. Kaplan E, Goodglass H, Weintraub S. Boston Naming Test. Philadelphia: Lea and Febiger, 1983.

14. Benton A. FAS Test. In: Spreen O, Benton A, eds. Neurosensory Center Comprehensive Examination for Aphasia. Victoria: University of Victoria, 1967.

15. Goodglass H, Kaplan E. Assessment of aphasia and related disorders. Philadelphia: Lea and Febiger, 1983.

16. Weschler D. WAIS-R manual. New York: Psychological Corp., 1981.

17. Mattis S. Mental status examination for organic mental syndrome in the elderly patient. New York: Grune and Stratton, 1976.

18. Rosen WG. The Rosen Drawing Test. Odessa: Psychological Assessment Resources, 1981. 
19. Benton AL. The Benton Visual Retention Test. New York: Psychological Corp., 1955.

20. Buschke H, Fuld PA. Evaluating storage, retention, and retrieval in disordered memory and learning. Neurology 1974; 24:1019-1025.

21. Stern Y, Andrews H, Pittman J, et al. Diagnosis of dementia in a heterogeneous population. Development of a neuropsychological paradigm-based diagnosis of dementia and quantified correction for the effects of education. Arch Neurol 1992; 49:453-460.

22. Pittman J, Andrews H, Tatemichi T, et al. Diagnosis of dementia in a heterogeneous population. A comparison of paradigm-based diagnosis and physician's diagnosis. Arch Neurol 1992;49:461-467.

23. McKhann G, Drachman D, Folstein M, Katzman R, Price D, Stadlan EM. Clinical diagnosis of Alzheimer's disease: report of the NINCDS-ADRDA Work Group under the auspices of Department of Health and Human Services Task Force on Alzheimer's Disease. Neurology 1984;34:939-944.

24. Roman GC, Tatemichi TK, Erkinjuntti T, et al. Vascular dementia: diagnostic criteria for research studies. Report of the NINDS-AIREN International Workshop. Neurology 1993;43: 250-260.

25. Hughes CP, Berg L, Danziger WL, Coben LA, Martin RL. A new clinical scale for the staging of dementia. Br J Psychiatry 1982;140:566-572.

26. Hatano S. Experience from a multicentre stroke register: a preliminary report. Bull WHO 1976;54:541-553.

27. 1990 Census of Population and Housing: summary tape file 1, technical documentation [computer program]. Washington, DC: Bureau of Census, 1991. STF 1A database.

28. Elias MF, Wolf PA, D'Agostino RB, Cobb J, White LR. Untreated blood pressure level is inversely related to cognitive functioning: the Framingham Study. Am J Epidemiol 1993; 138:353-364.

29. Sixth Report of the Joint National Committee on Prevention, Detection, Evaluation, and Treatment of High Blood Pressure. McLean, VA: International Medical Publishing, 1997:19.

30. Hixson JE, Vernier DT. Restriction isotyping of human apolipoprotein $\mathrm{E}$ by gene amplification and cleavage with HhaI. J Lipid Res 1990;31:545-548.

31. Maestre G, Ottman R, Stern Y, al. Apolipoprotein E and Alzheimer's disease: ethnic variation in genotypic risks. Ann Neurol 1995;37:254-259.

32. Kleinbaum DG, Klipper LL, Muller KE. Applied regression analysis and other multivariable methods. 2nd ed. Boston: PWS-Kent, 1988:601-631.

33. Zeger SL, Liang KY, Albert PS. Models for longitudinal data: a generalized estimating equation approach. Biometrics 1988; 44:1049-1060.

34. Breteler MM. Vascular risk factors for Alzheimer's disease: an epidemiologic perspective. Neurobiol Aging 2000;21:153-160.

35. Launer LJ, Masaki K, Petrovitch H, Foley D, Havlik RJ. The association between midlife blood pressure levels and late-life cognitive function. The Honolulu-Asia Aging Study. JAMA 1995;274:1846-1851.
36. Kilander L, Nyman H, Boberg M, Hansson L, Lithell H. Hypertension is related to cognitive impairment: a 20-year follow-up of 999 men. Hypertension 1998;31:780-786.

37. Kivipelto M, Helkala EL, Hanninen T, et al. Midlife vascular risk factors and late-life mild cognitive impairment: a population-based study. Neurology 2001;56:1683-1689.

38. Snowdon DA, Greiner LH, Mortimer JA, Riley KP, Greiner PA, Markesbery WR. Brain infarction and the clinical expression of Alzheimer disease. The Nun Study. JAMA 1997;277: 813-817.

39. SHEP Cooperative Research Group. Prevention of stroke by antihypertensive drug treatment in older persons with isolated systolic hypertension. Final results of the Systolic Hypertension in the Elderly Program (SHEP). JAMA 1991;265: 3255-3264.

40. Applegate WB, Pressel S, Wittes J, et al. Impact of the treatment of isolated systolic hypertension on behavioral variables. Results from the systolic hypertension in the elderly program. Arch Intern Med 1994;154:2154-2160.

41. Prince MJ, Bird AS, Blizard RA, Mann AH. Is the cognitive function of older patients affected by antihypertensive treatment? Results from 54 months of the Medical Research Council's trial of hypertension in older adults. Br Med J 1996;312: 801-805.

42. Di Bari M, Pahor M, Franse LV, et al. Dementia and disability outcomes in large hypertension trials: lessons learned from the Systolic Hypertension in the Elderly Program (SHEP) trial. Am J Epidemiol 2001;153:72-78.

43. Wang J, Staessen JA. Benefits of antihypertensive drug treatment in elderly patients with isolated systolic hypertension. Neth J Med 2001;58:248-254.

44. Hebert R, Lindsay J, Verreault R, Rockwood K, Hill G, Dubois M-F. Vascular dementia. Incidence and risk factors in the Canadian Study of Health and Aging. Stroke 2000;31:14871493.

45. Luchsinger JA, Tang M-X, Stern Y, Shea S, Mayeux R. Diabetes mellitus and the risk of Alzheimer's disease and dementia with stroke in a multiethnic cohort. Am J Epidemiol 2001;154: 635-641.

46. Kemper TL, Blatt GJ, Killiany RJ, Moss MB. Neuropathology of progressive cognitive decline in chronically hypertensive rhesus monkeys. Acta Neuropathol (Berl) 2001;101:145-153.

47. Harrington F, Saxby BK, McKeith IG, Wesnes K, Ford GA. Cognitive performance in hypertensive and normotensive older subjects. Hypertension 2000;36:1079-1082.

48. Cervilla JA, Prince M, Joels S, Lovestone S, Mann A. Longterm predictors of cognitive outcome in a cohort of older people with hypertension. Br J Psychiatry 2000;177:66-71.

49. Starr JM, Whalley LJ, Inch S, Shering PA. Blood pressure and cognitive function in healthy old people. J Am Geriatr Soc 1993;41:753-756.

50. Scherr PA, Hebert LE, Smith LA, Evans DA. Relation of blood pressure to cognitive function in the elderly. Am J Epidemiol 1991;134:1303-1315. 


\section{Neurology}

\section{The relationship of hypertension in the elderly to $\mathrm{AD}$, vascular dementia, and cognitive function}

H. B. Posner, M.-X. Tang, J. Luchsinger, et al.

Neurology 2000;58;1175-1181

DOI 10.1212/WNL.58.8.1175

\section{This information is current as of April 23, 2002}

\section{Updated Information \& Services}

\section{References}

\section{Subspecialty Collections}

Permissions \& Licensing

Reprints including high resolution figures, can be found at: http://www.neurology.org/content/58/8/1175.full.html

This article cites 39 articles, 16 of which you can access for free at: http://www.neurology.org/content/58/8/1175.full.html\#\#ref-list-1

This article, along with others on similar topics, appears in the following collection(s):

All Cognitive Disorders/Dementia

http://www.neurology.org//cgi/collection/all_cognitive_disorders_deme ntia

Alzheimer's disease

http://www.neurology.org//cgi/collection/alzheimers_disease

Cognitive neuropsychology in dementia

http://www.neurology.org//cgi/collection/cognitive_neuropsychology_i n dementia

Risk factors in epidemiology

http://www.neurology.org//cgi/collection/risk_factors_in_epidemiology

Vascular dementia

http://www.neurology.org//cgi/collection/vascular_dementia

Information about reproducing this article in parts (figures,tables) or in its entirety can be found online at:

http://www.neurology.org/misc/about.xhtml\#permissions

Information about ordering reprints can be found online: http://www.neurology.org/misc/addir.xhtml\#reprintsus

Neurology $®$ is the official journal of the American Academy of Neurology. Published continuously since 1951, it is now a weekly with 48 issues per year. Copyright . All rights reserved. Print ISSN: 0028-3878.

Online ISSN: 1526-632X.

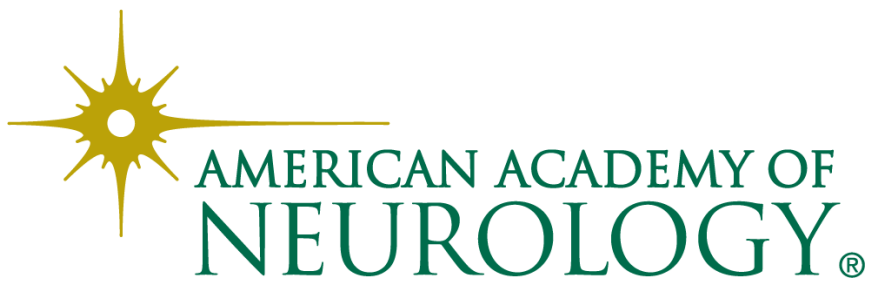

